\title{
Acute angle closure glaucoma precipitated by orbital pseudotumour
}

\author{
LILLY ZBOROWSKI-GUTMAN,' ISAAC GUTMAN,' VARDA CHEN,' \\ MORDECHAI SHARIR,' AND GIDEON FINDLER ${ }^{2}$
}

From the 'Goldschleger Eye Institute, Neuro-ophthalmology Unit, and 'Department of Neurosurgery, Chaim Sheba Medical Center, Tel Hashomer and Sackler School of Medicine, Tel Aviv University, Israel

SUMMARY A 62-year-old woman presented with acute angle closure glaucoma. After a poor response to conventional treatment the presenting signs were re-evaluated and a diagnosis of pseudotumour of the orbit was made. Treatment with oral steroids resolved both the glaucoma and the orbital pseudotumour. The presumed pathogenesis and literature are reviewed.

A secondary rise in intraocular pressure may have both ocular and orbital causes. Open angle glaucoma secondary to elevated episcleral venous pressure may result from orbital processes such as thyroid disease, pseudotumour, arterovenous malformation, and varices.' Secondary angle closure glaucoma can follow central retinal vein occlusion, ${ }^{2}$ buckling procedures $^{3}$ with reactive lymphoid hyperplasia, ${ }^{4}$ posterior scleritis, ${ }^{5}$ and in association with acquired immune deficiency syndrome (AIDS). ${ }^{6}$ We describe here a case of orbital pseudotumour that presented with acute angle closure glaucoma. Both the pseudotumour and the glaucoma resolved with systemic steroid treatment.

\section{Case history}

A 62-year-old white woman presented with a oneweek history of right periorbital pain. There was no previous ocular history. She had a past history of gastric ulcer.

On admission her visual acuity was 6/12 (20/40) in the right eye and 6/9 (20/30) in the left. Examination of the right eye revealed a soft swollen upper eyelid with full extraocular movements. Slit-lamp examination showed moderate chemosis and conjunctival injection. The cornea was clear. The anterior chamber depth was $2.0 \mathrm{~mm}$ with no flare or cells. The lens and vitreous were clear. Applanation tonometry

Correspondence to Isaac Gutman, MD, Neuro-ophthalmology Unit, Chaim Sheba Medical Center, Tel Hashomer 52621, Israel. revealed an intraocular pressure of $35 \mathrm{mmHg}$; gonioscopy showed a closed angle for $270^{\circ}$ and a slit angle in the lower quadrant. The pupil measured $4 \mathrm{~mm}$ in the dark and reacted sluggishly to light. Funduscopy showed a normal disc with $0 \cdot 2$ cup. The macula, blood vessels, and periphery were normal. In the left eye the eyelids were normal, a slit-lamp examination gave normal results, and the intraocular pressure was $14 \mathrm{mmHg}$. The anterior chamber depth was $2.2 \mathrm{~mm}$

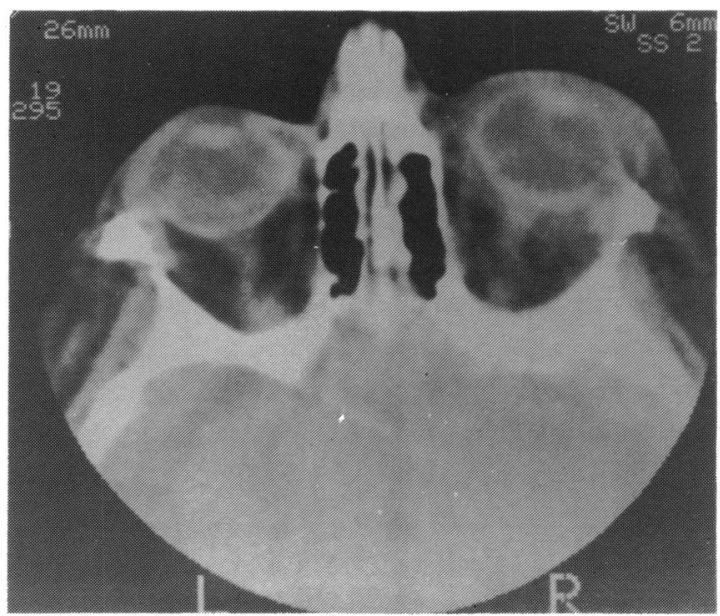

Fig. 1 Axial CT scan without contrast demonstrates right exophthalmos with lid swelling, thickened sclera in the posterior aspect of the right globe, and retrobulbar tissue swelling. 


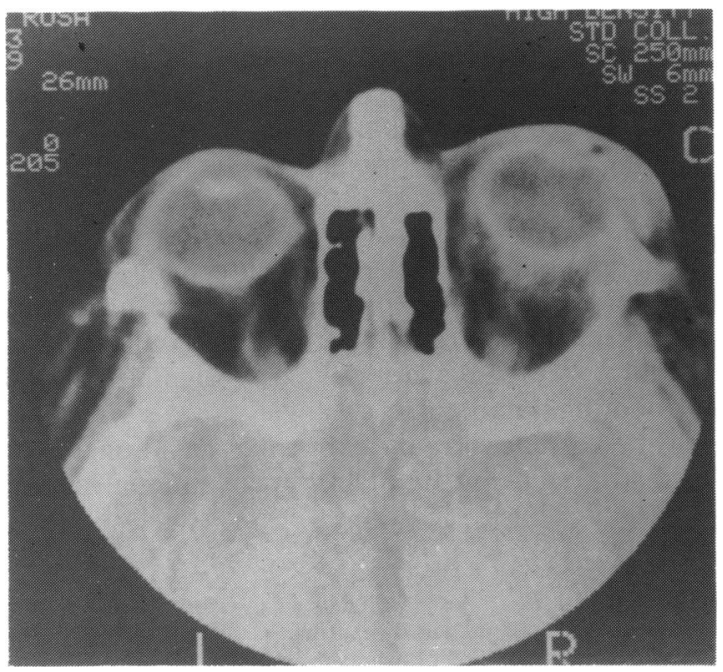

Fig. 2A Axial CTscan with contrast demonstrates right scleral enhancement.

and the angle was open to grade 3 for $360^{\circ}$ with a slightly narrow entrance.

A trial of pilocarpine, acetazolamide, and glycerol lowered the pressure only transiently, and over the next 24 hours her condition deteriorated. Right exophthalmos of $4.5 \mathrm{~mm}$ developed, the chemosis became severe, and the extraocular movement became markedly restricted. There was resistance to retropulsion of the globe, but no mass was palpated. The anterior chamber shallowed to $1.6 \mathrm{~mm}$, and fundus examination revealed a few choroidal folds near the macula.

The erythrocyte sedimentation rate (ESR) was 103 $\mathrm{mm} / \mathrm{h}$ and the leucocytes $13 \times 10^{4} \mathrm{l}(90 \%$ polymorphonuclear). The blood sugar was mildly raised at $172 \mathrm{mg} / 100 \mathrm{ml}(9.5 \mathrm{mmol} / \mathrm{l})$. Other laboratory data including thyroxin levels were normal. CT scanning done on the same day showed thickened sclera and enhanced retrobulbar soft tissue on the right side (Figs. 1,2). The left side was normal.

The patient was started on $60 \mathrm{mg}$ prednisone orally with cimetidine. Within six hours there was a dramatic clinical improvement. The pain, swelling, and chemosis decreased markedly. The extraocular movements became normal. The anterior chamber deepened to $2.1 \mathrm{~mm}$, the intraocular pressure dropped to $15 \mathrm{~mm}$, and the angle opened to grade III for $270^{\circ}$; the nasal quadrant was sealed by peripheral anterior synechiae.

On discharge from hospital her visual acuity in the right eye was $6 / 9+(20 / 30+)$ and intraocular pressure was $15 \mathrm{mmHg}$. There was no exophthalmos, chemosis, or restricted ocular movements. The

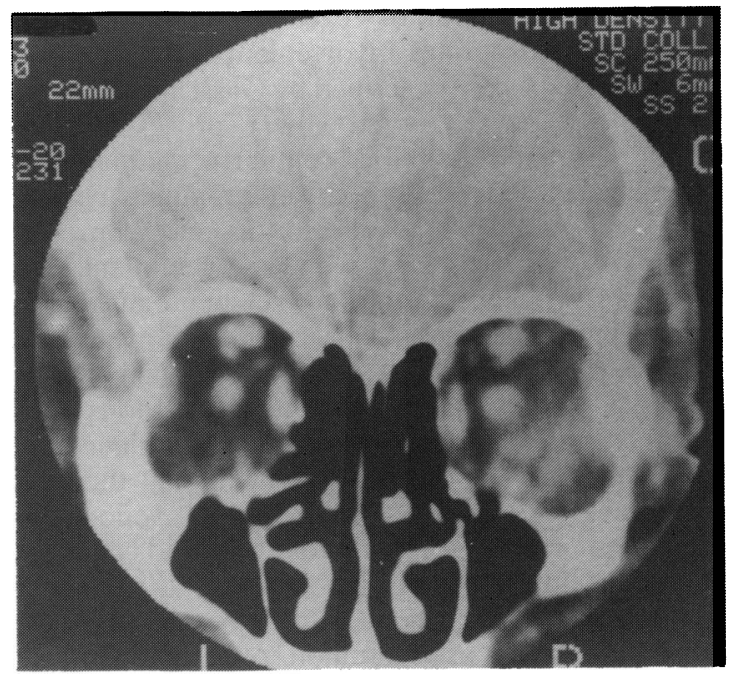

Fig. 2B Coronal CT scan with contrast enhancement demonstrates swelling of retrobulbar soft tissue in the right orbit.

steroid dose was gradually tapered. The patient has remained asymptomatic for 18 months. Repeated CT scans showed a normal globe and orbit (Fig. 3).

\section{Discussion}

Orbital pseudotumour can affect men and women at any age, though middle age is most usual. Pain and proptosis are the commonest features. Glaucoma occasionally occurs and is usually caused by raised episcleral venous pressure. The diagnosis of pseudotumour of the orbit can be reliably confirmed by CT scan, and the response to steroids is usually prompt.

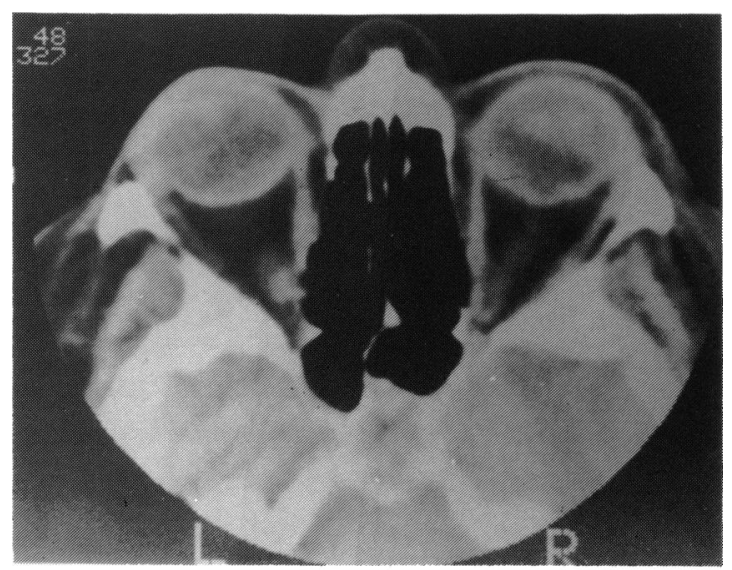

Fig. 3 Axial CT scan without contrast. All pathological features disappeared. 
Uveal pseudotumour or reactive lymphoid hyperplasia without orbital involvement has been described. ${ }^{+7}$ In the case described by Gass ${ }^{4}$ angle closure developed, and engorged ciliary processes were visible through the pupil. Similarly Quinlan and Hitchings ${ }^{5}$ described three cases of angle closure glaucoma with posterior scleritis and choroidal effusions. Their cases responded to treatment with systemic oxyphenbutazone and cyclopentolate drops. In the present case ciliary processes were not observed, and the fundus was fairly normal. Harris and Rice ${ }^{8}$ described a woman with a cavernous sinus carotid fistula who developed angle closure glaucoma. The glaucoma responded to conventional therapy. They suggested that generalised orbital venous engorgement caused uveal engorgement and compression of the anterior segment.

We believe the present case to be the first description of orbital pseudotumour precipitating angle closure glaucoma. The pathogenesis was probably similar to the case of Harris and Rice-that is, orbital congestion causing relative obstruction of the vortex veins. The swelling of the uvea pushed the iris-lens diaphragm forward, shallowing the chamber and closing the angle. Unlike the case of Harris and Rice our patient did not respond to pilocarpine but rather to treatment of the underlying condition (pseudotumour) with steroids. Pilocarpine may have further exacerbated the situation by inducing forward movement of the ciliary body. In contrast, cyclopentolate drops might have been useful until the improvement of the orbital congestion by the steroids.

In our patient the contralateral eye had a slightly narrow entrance to the angle recess. We can assume that the affected eye had a similar appearance before the onset of the pseudotumour. In the normal course of events such an eye may have been only at moderate risk for developing angle closure. However, given the additional stimulus of a pseudotumour and presumed uveal swelling, frank angle closure developed.

Other cases of secondary angle closure in orbital pseudotumour may have gone unrecognised in the past because of the difficulty of measuring the intraocular pressure and performing gonioscopy in the presence of severe chemosis. Signs of orbital pseudotumour in cases of angle closure glaucoma may necessitate steroid treatment as an adjunct to or instead of breaking the attack by conventional means.

\section{References}

1 Yablonski ME, Podos SM. Glaucoma secondary to elevated episcleral venous pressure. In: Ritch $\mathrm{R}$, Shields MB, eds. The secondary glaucomas. St Louis: Mosby, 1982: 207-17.

2 Hyams SW, Neumann E. Transient angle-closure glaucoma after retinal vein occlusion. Report of two cases. BrJ Ophthalmol 1972; 56: $353-5$.

3 Phelps CD. Glaucoma associated with retinal disorders. In: Ritch $\mathrm{R}$, Shields MB, eds. The secondary glaucomas. St Louis: Mosby, 1982: 153-6.

4 Gass JP. Retinal detachment and narrow angle glaucoma secondary to inflammatory pseudotumor of the uveal tract. $A m J$ Ophthalmol 1967; 64: 612-21.

5 Quinlan MP, Hitchings RA. Angle-closure glaucoma secondary to posterior scleritis. BrJ Ophthalmol 1978; 62: 330-5.

6 Ullman S, Wilson RP, Schwartz L. Bilateral angle closure glaucoma in association with the acquired immune deficiency syndrome. Am J Ophthalmol 1986; 101: 419-24.

7 Ryan SJ, Frank RN, Green WR. Bilateral inflammatory pseudomotor of the ciliary body. Am J Ophthalmol 1971; 72: 586-91.

8 Harris GJ, Rice PR. Angle closure glaucoma in carotid cavernous fistula. Ophthalmology 1979; 86: 1521-9.

Accepted for publication 4 December 1986. 